of synthetics; the corresponding figure for the rest of the world (excluding Communist countries) is 25 per cent, but this is likely to increase with the opening of the new plants. 'The year does not appear to have produced any outstanding new technical developments but rather a steady improvement of materials and techniques. The report contains more than one thousand references to scientific and technical publications, although, as is inevitable in a work of this kind, there is some overlapping from section to section.

\section{Aerial Photographic Exhibition of Quarries and Mines}

A specral exhibition of aerial photographs of quarries and mines opened at the Geological Museum, Exhibition Road, London, S.W.7, on October 15. Admission is free. The exhibition will remain open for several months. The photographs show past and present surface aspects and effects of quarrying and mining in the United Kingdom, and illustrate the great variety of useful rocks and minerals found in Britain. All the photographs are from the Cambridge University Collection, an extensive library of air photographs specially selected to meet needs of teaching and research. They have been taken during recent years by Dr. J. K. S. St. Joseph, curator in aerial photography at Cambridge, from aircraft of the Royal Air Force on training flights.

\section{Petroleum Industry in Great Britain}

THE Petroleum Information Bureau has published under the title "U.K. Petroleum Industry Statistics relating to Consumption and Refinery Production, 1957 and 1958' (Pp. 10. London: Petroleum Information Bureau, 1959) figures covering all petroleum products, whether imported or from indigenous sources, as well as substitutes such as benzole and hydrogenated spirits. Refinery production figures do not count further treatment of finished products for special grades. The figures relate to 1957 and 1958 , in which deliveries and consumption of petroleum products totalled $24,784,586$ tons and $31,065,629$ tons, respectively.

\section{New Journal of Giass Technology}

MoRe and more problems in the physies and chemistry of glasses are being investigated in laboratories all over the world. At present the results are published in many non-specialized journals and the time has come to provide a vehicle for these papers. The Society of Glass Technology has therefore decided that from February 1960 its Journal should be published in two parts. These will be called Glass Technology and Physics and Chemistry of Glasses. Both journals will contain papers, abstracts, communications to the editor and book reviews. Arrangements are being made with the Abstracting Board of the International Council of Scientific Unions to ensure that papers published in these new journals will be abstracted as widely as possible and also that the abstract sections will be comprehensive. Glass Technology will contain reports of applied science in the glass industry, and subjects considered suitable include : control of batch compositions; corrosion of refractories; design, operation and performance of furnaces; methods of chemical and physical testing; melting processes; statistical analysis of industrial experimentation. In Physics and Chemistry of Glasses will be published reports of original studies of the physics and chemistry of glasses, both experi- mental and theoretical. Possible subjects include : electrical properties; infra-red absorption; relaxa. tion processes ; thermodynamics of the glassy state ; viscosity ; X-ray diffraction. Copies of the Society's notes for authors are available from Prof. $R$. W. Douglas, Society of Glass Technology, Thornton, Hallam Gate Road, Sheffield 10.

\section{Plant Nematology}

$X_{T}$ is now recognized that eelworm diseases are among the most important problems in plant health and there has been a rapid increase in the study of plant parasitic nematodes in all countries where the growing of plants has become an organized industry. Unfortunately, there is a shortage of trained specialists in nematology and of introductory literature on the subject. The Ministry of Agriculture's new Technical Bulletin No. 7 (Pp. vii $+175+12$ plates. London: H.M. Stationery Office, $1959.9 s .6 d$. net) provides a general introduction and is based on the lectures given at a special training course held at the National Agricultural Advisory Service regional headquarters, Bristol, in 1956. It also reviews the more important nematode problems in British agriculture and is in part designed as a companion volume to Technical Bulletin No. 2 (Laboratory Methods for Work with Plant and Soil Nematodes). Although primarily designed for nematologists it should also be of interest to agricultural entomologists, plant pathologists and others who have to advise on eelworm problems and also to students and teachers of zoology, agriculture and parasitology. It contains 21 articles by research and advisory workers, arranged in six main sections covering the general structure and classification of nematodes, the more important genera, several practical and rosearch problems with cyst-forming eelworms, control and cultural studies.

\section{Sea Fisheries Research in East Africa}

THE annual report for 1958 of the East African Marine Fisheries Research Organization (pp. 20. Nairobi : Government Printer, 1959. 4s.) is one that reflects great credit on the small staff at Zanzibar. Research on the fish and fish-stocks of the Indian Ocean, first at Mauritius and now at Zanzibar, has been the post-war concern of the director, Dr. R. H. Wheeler, and it is good to learn from him that the phase during which it has been of first necessity to identify species is passing. In spite of the need to do systematic work, Dr. Wheeler, operating from Mauritius with a small converted fishing vessel, had already discovered a large and potentially rewarding line fishery in the neighbourhood of Seychelles Banks. The same vessel was transferred to Zanzibar, but during 1957 it was replaced by a large and more serviceable trawler, the Manihine. Among other tasks assigned to Manitine was floating long-line fishing for yellow-fin tuna and striped marlin. Using seven miles of line and two hundred and fifty hooks on or below the thermocline at 50-70 fathoms, heavy catches were made. These results are most encouraging for all those who wish to see the Colonies, Dependencies and emerging Commonwealth countries of Africa break into the oceanic resources of pelagic fish now so largely in the hands of the Japanese.

\section{Translocation of Amino-Acids}

THE translocation of carbon-14-labelled aminoacids and amides in the stems of young soyabean 